\title{
Reuse of effluent from dyeing process of polyamide fibers modified by double barrier discharge (DBD) plasma
}

\author{
Fernando Ribeiro Oliveira ${ }^{\mathrm{a}}$, Fernanda Steffens ${ }^{\mathrm{b}}$, Antonio Pedro Souto ${ }^{\mathrm{b}}$, Andrea Zille ${ }^{\mathrm{b}, *}$ \\ ${ }^{a}$ Federal University of Rio Grande do Norte, Campus Universitário, CT, DET, Av. Salgado Filho, 3000, Lagoa Nova, Natal, RN \\ 59078-970, Brazil, Tel.+55 849814 4994; email: fernandomoc@hotmail.com \\ ${ }^{b} 2$ C2T-Centro de Ciência e Tecnologia Têxtil, Departamento de Engenharia Têxtil, Universidade do Minho, 4800-058 Guimarães, \\ Portugal, Tel. +351 253 510280; emails: fernanda_steffens@hotmail.com (F.Steffens), souto@det.uminho.pt (A.P. Souto), \\ Tel. +351 253510285; email: azille@2c2t.uminho.pt (A. Zille)
}

Received 15 October 2014; Accepted 4 February 2015

\begin{abstract}
Low-temperature plasma technology becomes more and more attractive compared with traditional wet processes in textile preparation and finishing due to its high efficiency and low environmental impact. The objective of this study was to investigate the influence of dielectric barrier discharge plasma treatment on the trichromic dyeing process of polyamide 6.6 (PA66) and the reuse of the generated effluents for new dyeing processes. Chemical and physical characterization of the plasma-treated polyamide fibers was studied by means of static and dynamic contact angle, X-ray photoelectron spectroscopy (XPS), scanning electron microscopy micrographs, and atomic force microscopy (AFM). Plasma treatment greatly increases the hydrophilicity and adhesion of PA66, due to the increase of polar groups and roughness on the fibers surface as confirmed by XPS and AFM. The kinetics of dyeing is quicker but leveled with high rubbing, light, and washing fastness quality. The reuse of the effluent obtained after dyeing of the plasma-treated fabrics showed excellent results of reproducibility, uniformity, and washing fastness. It was possible to reproduce the standard color for three dyeing cycles using the same effluent reducing the effluent load with a significant diminution in costs and environmental impact.
\end{abstract}

Keywords: Dielectric barrier discharge (DBD); Dyeing; Direct dye; Plasma; Polyamide; XPS; Recycling; Effluent

\section{Introduction}

In recent years, textile industry in developed countries is challenging an increasing global competition due to the changed world market conditions.

${ }^{*}$ Corresponding author.
Moreover, the increasing environmental and health concerns owing to the large quantities of water and hazardous chemicals used in the conventional textile finishing techniques lead to the development of new technologies [1]. In this context, in recent decades, plasma technology has assumed a great importance among all available surface modification processes. It

Presented at the International Congress on Water, Waste and Energy Management 16-18 July 2014, Porto, Portugal

1944-3994/1944-3986 @ 2015 Balaban Desalination Publications. All rights reserved. 
is a dry, environmental- and worker-friendly method to achieve surface alteration without modifying the bulk properties of the materials [2]. In particular, nonthermal plasmas are especially suited because most textile materials are heat-sensitive polymers [3]. Since the temperature of non-thermal plasmas is relatively low, the activating species in plasma will easily lose their energy once they have reacted with the polymer material. As a result, the penetration of the plasma into the polymer materials is so shallow that the interior of the material is only slightly affected. Plasma treatment can be used as an effective technique for modifying the surface properties of textile fabrics without significant alteration of the interior part of the fibers, as the plasma species can penetrate only to a depth of about $1,000 \AA$ [4]. In this context, as a pretreatment to dyeing process, the plasmatic discharge is able to modify or remove the fiber-hydrophobic outer layer, improving dye-fiber interaction, and increasing the flux of dye molecules through the fiber surface into the fiber bulk [5]. In general, conventional dyeing processes have a low yield, and the percentage of dye lost in the effluents can reach up to $50 \%$. Besides the obvious esthetic problem, dye wastewaters without an appropriate treatment can persist in the environment for extensive periods of time and are deleterious not only for the photosynthetic processes of the aquatic plants, but also for all the living organisms since the degradation of these can lead to carcinogenic substances [6]. The dyeing rate, dyebath exhaustion, and dyeing uniformity are highly improved by plasma treatment $[1,7,8]$. Excellent results were obtained by dyeing polyamide (PA) fabrics with acid, direct, and reactive dyes after dielectric barrier discharge (DBD) plasma treatment. The chemical and physical effects of the plasma discharge, such as the formation of strong bonds between the dye and the PA fibers contribute to achieve high levels of coloristic and fastness properties $[2,9]$. The possibility of reusing the water effluent also contributes to a reduction of the effluent load with a significant diminution in costs and environmental impact [10]. Nowadays, several physicochemical and biological methods have been developed to treat dye-containing wastewaters [11]. Each technique has its own advantages and drawbacks, but these methods generally imply higher energy/operation costs [12]. However, significant cost reduction can be achieved providing an efficient penetration and binding of the dye molecules into textile fibers in order to strongly reduce dye waste into the effluent. Plasma treatment is the ideal solution because not only allows high level of direct dye diffusion and fixation in polyamide 6.6 (PA66) fibers at lower temperatures and shorter dyeing times than traditional dyeing methods, but also, promote the formation of micro-channels and low-molecular weight acidic molecules, from the breakages of the PA chains, that act as dye "carrier" favoring dye diffusion into the fiber cores $[1,13]$. Thus, the main objective of this study aims to investigate the physicochemical improvements occasioned by DBD plasma discharge in dyeing process of PA66 fibers and the possibility to reuse the effluent obtained for a new dyeing process. The structural and chemical modifications of fabrics were further analyzed in terms of static and dynamic contact angle, Scanning electron microscopy (SEM), atomic force microscopy (AFM), energy dispersive X-ray spectroscopy (EDS), and X-ray photoelectron spectroscopy (XPS) techniques. Moreover, the tinctorial behavior (color strength and exhaustion) of the PA fabric dyed with direct dyes, in a single dyebath containing three dyes, was studied by the use of reflectance and absorbance spectrophotometers.

\section{Materials and methods}

\subsection{Material}

Commercial PA66 fabric with a warp density of 40 threads $\mathrm{cm}^{-1}$, a weft density of 30 threads $\mathrm{cm}^{-1}$, and a surface density of $95 \mathrm{~g} / \mathrm{m}^{2}$ was used in this study. The samples were pre-washed with a $1 \mathrm{~g} / \mathrm{L}$ of nonionic detergent solution at $30^{\circ} \mathrm{C}$ for $30 \mathrm{~min}$ and then rinsed with water for another $15 \mathrm{~min}$, before DBD plasma treatment, in order to minimize contaminations. The direct dyes Sirius Blue K-CFN, Sirius Orange 3GDL, and Sirius Scarlet K-CF (C.I. Direct Blue 9, Direct Orange 57, Direct Red 89, respectively) were supplied by Dystar Textilfarben, Frankfurt, Germany. All the other reagents were analytical grade purchased from Sigma-Aldrich, St. Louis, MO, USA and used without further purification.

\subsection{DBD plasma treatment}

DBD plasma treatment of PA fabric was carried out in a semi-industrial prototype machine (Softal Electronics $\mathrm{GmbH} /$ University of Minho) working at room temperature and atmospheric pressure, using a system of metal electrode coated with ceramic and counter electrodes coated with silicon with $50 \mathrm{~cm}$ effective width, gap distance fixed at $3 \mathrm{~mm}$, and producing the discharge at high voltage $10 \mathrm{kV}$ and low frequency $40 \mathrm{kHz}$ (Fig. 1). The discharge power supplied by the electrodes and the speed may vary, with maximum discharge of $1.5 \mathrm{~kW}$ and speed of $60 \mathrm{~m} / \mathrm{min}$. The machine was operated at the optimized parameters: $1 \mathrm{~kW}$ of power, velocity of $4 \mathrm{~m} / \mathrm{min}$, five passages 


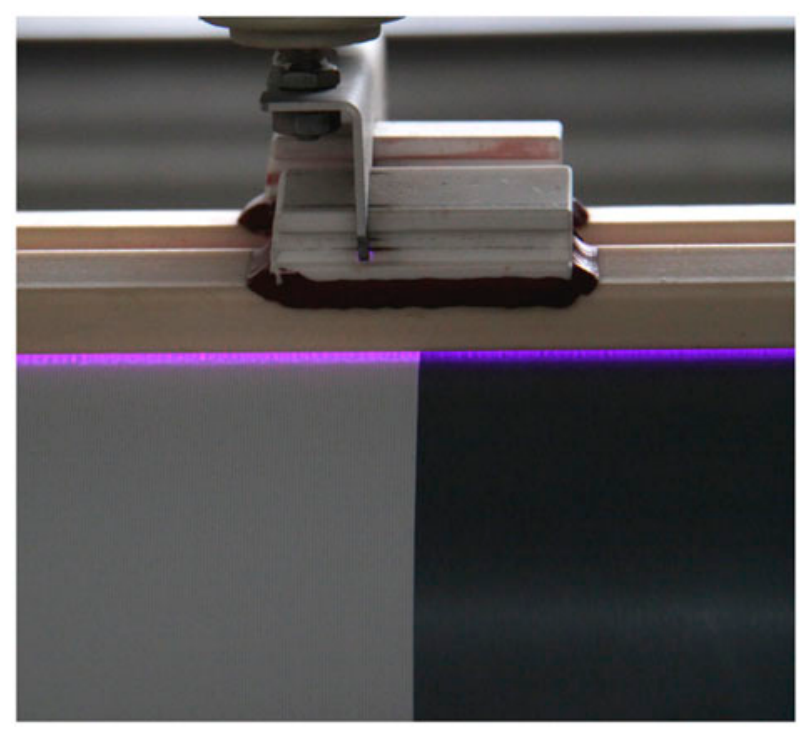

Fig. 1. A PA fabric passing through the DBD atmospheric plasma discharge generated between the ceramic and silicon-coated electrodes.

corresponding to a dosage of $2.5 \mathrm{~kW} \mathrm{~min} / \mathrm{m}^{2}$ as previously reported [5]. Plasmatic dosage was defined by Eq. (1):

Dosage $=\frac{N \cdot P}{v \cdot l}$

where $N=$ number of passages, $P=$ power $(W)$, $v=$ velocity $(\mathrm{m} / \mathrm{min})$, and $l=$ width of treatment (0.5 m).

\subsection{Contact angle measurements}

Dataphysics equipment using OCA20 software with video system for the capturing of images in static and dynamic modes was used to evaluate the wettability of the PA woven fabrics. A water-drop test was applied by measuring the time for its complete absorption into the material.

\subsection{X-ray photoelectron spectroscopy (XPS)}

XPS measurements were performed on a VG Scientific ESCALAB 200A equipment with PISCES software for data acquisition and analysis. For analysis, an achromatic $\mathrm{Al}(\mathrm{Ka}) \mathrm{X}$-ray source operating at $15 \mathrm{kV}$ $(300 \mathrm{~W})$ was used, and the spectrometer, calibrated with reference to $\mathrm{Ag} 3 \mathrm{~d} 5 / 2(368.27 \mathrm{eV})$, was operated in $\mathrm{CAE}$ mode with $20 \mathrm{eV}$ pass energy. Data acquisition was performed with a pressure lower than $1 \mathrm{E}^{-6} \mathrm{~Pa}$. Deconvolution into subpeaks was performed by least-squares peak analysis software, XPSPEAK version 4.1, using the Gaussian/Lorenzian sum function and Shirley-type background subtraction (or linear consideration of the data).

\subsection{Scanning electron microscopy (SEM) and energy dispersive X-ray spectroscopy (EDS)}

Morphological analyses of PA samples were carried out with an ultra-high resolution field emission gun scanning electron microscopy, NOVA 200 Nano SEM, FEI Company. Secondary electron images were performed with an acceleration voltage between 5 and $10 \mathrm{kV}$. Backscattering electron images were made with an acceleration voltage of $15 \mathrm{kV}$. Samples were covered with a film of Au-Pd (80-20 weight \%) in a high-resolution sputter coater, 208HR Cressington Company, coupled to with a MTM-20 Cressington High Resolution Thickness Controller. Atomic compositions of the fabrics were examined with the EDS capability of the SEM equipment using an EDAX Si (Li) detector and an acceleration voltage of $5 \mathrm{kV}$.

\subsection{Atomic force microscopy (AFM)}

AFM experiments were performed in a tapping mode in air using a Multimode AFM from Agilent, model 5500, at room temperature. Silicon cantilevers (AppNano) with a constant force between 25 and 75 $\mathrm{N} / \mathrm{m}$ and a resonance frequency of $339 \mathrm{kHz}$ were used. The PicoView 1.10 software version was used for the simultaneous recording of the topography, phase, and amplitude magnitudes of the images.

\subsection{Dyeing methods}

Samples were dyed with three different combinations of the dyes, according to Table 1, in distilled water without auxiliaries, using a dye total concentration of $1 \% \mathrm{spm}$. Dyeing tests were carried out in a laboratorial "Ibelus" machine equipped with infrared heating with a liquor ratio of 1:40 and $\mathrm{pH}$ around 4.5 using stainless steel dye pots with $200 \mathrm{~cm}^{3}$ of capacity each. The program was started at $20^{\circ} \mathrm{C}$ and raised at a rate of $2^{\circ} \mathrm{C} / \mathrm{min}$ up to $98^{\circ} \mathrm{C}$, and kept at this temperature for $60 \mathrm{~min}$. Then, the system was cooled at a rate of $2^{\circ} \mathrm{C} / \mathrm{min}$ up to $60^{\circ} \mathrm{C}$. The absorption measurements for the calculation of dyebath exhaustion process with direct dye were obtained in a Unicam UV-vis UV2 spectrophotometer. 
Table 1

Trichromic direct dyes and relative concentrations used to study the reuse of the effluent obtained (dyeing conditions: pH 4.5 ; temperature: $98^{\circ} \mathrm{C}$ e RB: $1: 40$ )

\begin{tabular}{llll}
\hline Dyes & Blue K-CFN (\%) & Orange 3DGL (\%) & Scarlet K-CF (\%) \\
\hline Color 1 & 0.50 & 0.25 & 0.25 \\
Color 2 & 0.25 & 0.50 & 0.25 \\
Color 3 & 0.25 & 0.25 & 0.50 \\
\hline
\end{tabular}

\subsection{Color strength}

The relative color strength $(K / S$ values) was then established at standard illuminant D65 (LAV/Spec. Excl., d/8, D65/10 ${ }^{\circ}$, according to the Kubelka-Munk equation, where $K$ and $S$ stand for the light absorption and scattering, respectively. The shift of the coordinates of the color in the cylindrical color space, based on the theory that color is perceived by black-white $\left(L^{*}\right.$, lightness), red-green $\left(a^{*}\right)$, and yellow-blue $\left(b^{*}\right)$ sensations, was summarized by the overall color difference $\left(\Delta E^{*}\right)$ value. The value of $\Delta E^{*}$ represents the overall color difference between the sample and the standard.

\subsection{Washing, light, and rubbing fastness}

The washing fastness was evaluated in accordance to the stipulated in standard ISO $105 \mathrm{C} 06$, method A1S, at temperature of $40^{\circ} \mathrm{C}$. The rubbing fastness was evaluated according to standard ISO 105 X12:2001. The light fastness was performed in the Accelerated Weathering Tester (QUV) Spray LU-0819 from Q-PANEL, equipped with UVA 340 lamp, at $70^{\circ} \mathrm{C}$ and irradiation at $77 \mathrm{Wm}^{-2}$ for light fastness test. The QUV test chamber simulated weather conditions. Exposure cycles of $2,4,8,12,24$, and $48 \mathrm{~h}$ were applied on samples until remarkable color degradation was observed.

\section{Results and discussion}

\subsection{Static and dynamic contact angle}

The surface properties of untreated and plasmatreated PA66 fabrics were analyzed by static and dynamic contact angle measurements based on the sessile drop principle using water. According to data attained in Fig. 2, the static contact angle for the untreated PA fabric was $145.8^{\circ}$, being considered as hydrophobic. Five different discharge dosages $(0.5,1$, $2,2.5$, and $3 \mathrm{~kW} \mathrm{~min} / \mathrm{m}^{2}$ ) were tested in order to optimize the plasmatic effect onto the PA66 surface. After plasma treatment, a clear increase in surface polarity and wettability was observed. In fibrous materials, it is difficult to precisely measure contact angles by the static approach because a smooth transition area exists between a solid and a liquid [14]. Indeed, despite the values of the static contact angle at low energy dosage $\left(0.5 \mathrm{~kW} \mathrm{~min} / \mathrm{m}^{2}\right)$ remained relatively high, the dynamic contact angles of the untreated and plasmatreated samples showed significant differences. The times for the complete absorption of the water drop for the untreated samples were higher than a minute. After plasma treatment, the values decrease to less than one second for all the DBD plasma dosages. The PA synthetic fiber changes the nature from hydrophobic to hydrophilic, which is the key point for the adsorption of aqueous dye solutions. The fabric treated with a plasma dosage of $2.5 \mathrm{~kW} \mathrm{~min} / \mathrm{m}^{2}$ showed almost instantaneous water absorption and was used as model for this work. Further, plasma-energy dosages did not lead to significant differences in hydrophilicity. These results suggest that the surface of the treated PA samples have been significantly changed due to chemical etching, which tends to create oxidized species on the surface of the PA fibers $[15,16]$. It also suggests that enhanced polar contribution at the plasma-treated PA surface could be attributed to a reorientation of the polar groups toward the fiber surface [17].

\subsection{Energy dispersive spectroscopy and X-ray photoelectron spectroscopy}

The EDS and XPS analysis of the PA fibers are shown in Table 2. For the samples treated with DBD air plasma, EDS analysis shows that when the dosage is increased, the carbon content on the surface of the sample decreases. On the other hand, the oxygen and nitrogen elements increase when the DBD plasma treatments are applied. Etching may provoke chain scission in groups $\mathrm{C}-\mathrm{H}, \mathrm{C}-\mathrm{O}, \mathrm{C}-\mathrm{N}, \mathrm{N}-\mathrm{H}$, and the formation of free radicals, causing the measured carbon content to decrease. Other surface reactions with air plasma can occur to produce reactive species, such as $\mathrm{O}^{-}, \mathrm{N}, \mathrm{N}^{+}, \mathrm{O}, \mathrm{OH}^{-}, \mathrm{O}_{3}$, which would also result in carbon decrease and increase of nitrogen and oxygen atoms $[18,19]$. There are extensive academic studies using XPS technique in fabrics after plasma treatment, 


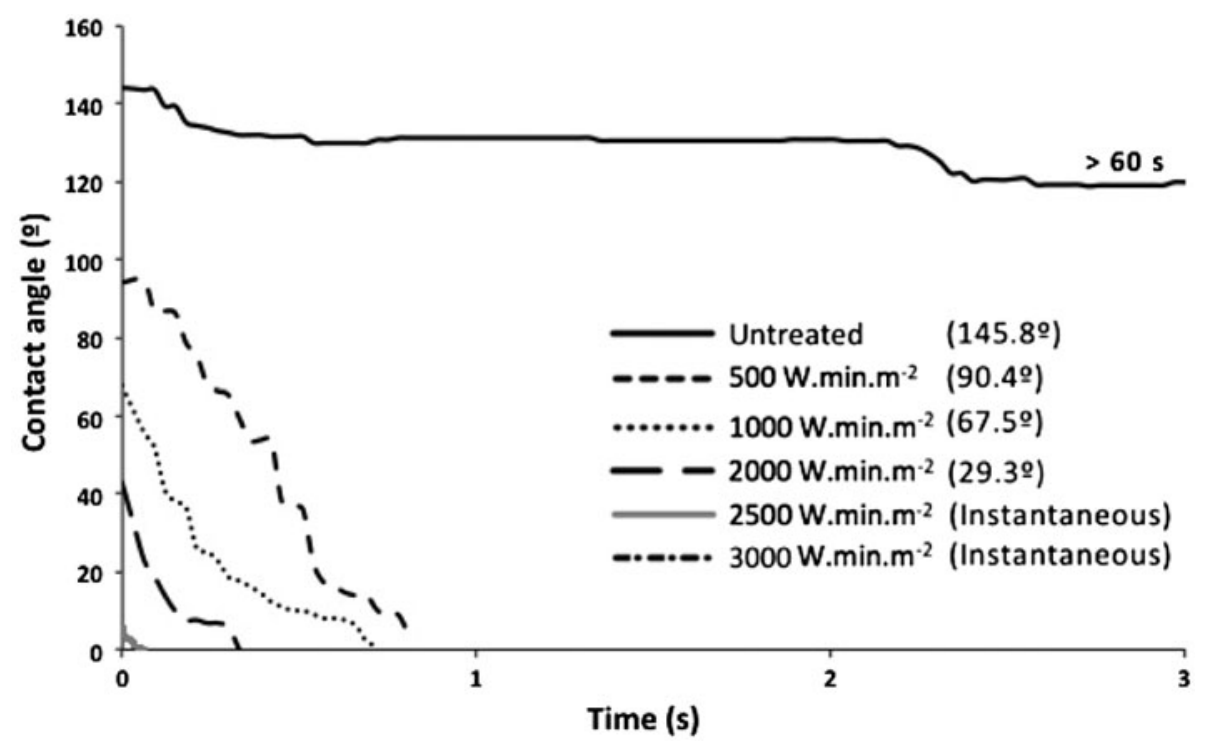

Fig. 2. Static (in bracket) and dynamic contact angles of plasma-treated PA66 fabric at different energy dosages.

Table 2

Relative chemical composition and atomic ratio determined by EDS and XPS of untreated (U) and plasma-treated (P) PA66 fabrics

\begin{tabular}{llllllll}
\hline & & \multicolumn{2}{l}{ At $(\%)$} & & & \multicolumn{2}{c}{ Atomic ratio } \\
\cline { 3 - 4 } & & $\mathrm{C}$ & $\mathrm{O}$ & $\mathrm{N}$ & & $\mathrm{O} / \mathrm{C}$ & $\mathrm{N} / \mathrm{C}$ \\
\hline \multirow{2}{*}{ EDS } & $\mathrm{U}$ & 67.38 & 22.67 & 9.95 & & 0.33 & 0.15 \\
& $\mathrm{P}$ & 64.05 & 25.13 & 10.82 & & 0.39 & 0.17 \\
XPS & $\mathrm{U}$ & 74.67 & 17.75 & 7.58 & & 0.23 & 0.10 \\
& $\mathrm{P}$ & 70.25 & 19.83 & 9.92 & & 0.28 & 0.14 \\
\hline
\end{tabular}

in order to clarify chemical surface modifications $[20,21]$. Table 2 also shows that the oxygen and nitrogen content level in PA is increased after DBD treatment, which is in accordance to EDS analysis. This indicates a substantial incorporation of these atoms $(\mathrm{O}$ and $\mathrm{N})$ onto the fabric surface. However, due to the low energies involved in this specific treatment, the difference in nitrogen content could also come from a surface cleaning effect that allows the fingerprint of the material bulk to appear on the spectra [22,23]. It is clear that the plasma treatment is able to increase the concentration of polar groups near the surface of the fabric mainly by the incorporation of oxygen atoms from atmospheric air, which significantly increases wettability [22,24].

\subsection{Scanning electron microscopy and atomic force microscopy}

SEM analysis of the PA fabric before and after treatment gives information about the etching function of the double barrier discharge plasma. Borcia et al. observed a localized strong melting of the polyester fibers, where the bundles of fibers are crossing each other [25]. In another study, the micrographs obtained for the plasma exposed nylon films revealed the presence of micropits after $25 \mathrm{~s}$ of treatment [26]. Fig. 3(A) and (B) shows the results of control and plasma-treated PA with magnification of 10,000X. The topography of the untreated sample was very smooth, while a submicron ripples appear at the surface of plasmatreated samples induced by the highly reactive and energetic plasma species that promoting synthetic fiber ablation (etching) and increase fiber surface roughness and hydrophilicity-dependent properties.

AFM measurements were performed to obtain the tridimensional representation of the topography of the untreated and plasma-treated PA66 fibers as well as to evaluate its roughness (Fig. 3(C) and (D)). The threedimensional representation $\left(200 \times 200 \mathrm{~nm}^{2}\right)$ of the plasma-treated sample clearly shows an increase in the surface roughness of the fibers due to plasma etching with the appearance of valleys and peaks. This increase in roughness creates a higher surface energy, decreasing the water drop contact angle, and allowing a better physical interaction between the fabric and the dye molecules [27].

\subsection{Dyeing results and reuse of the effluent}

Plasma pre-treatment allows the dyeing of nylon with direct dyes without auxiliaries and at lower temperature and dye concentration [28]. Moreover, despite the well-known aging effect of the plasma 

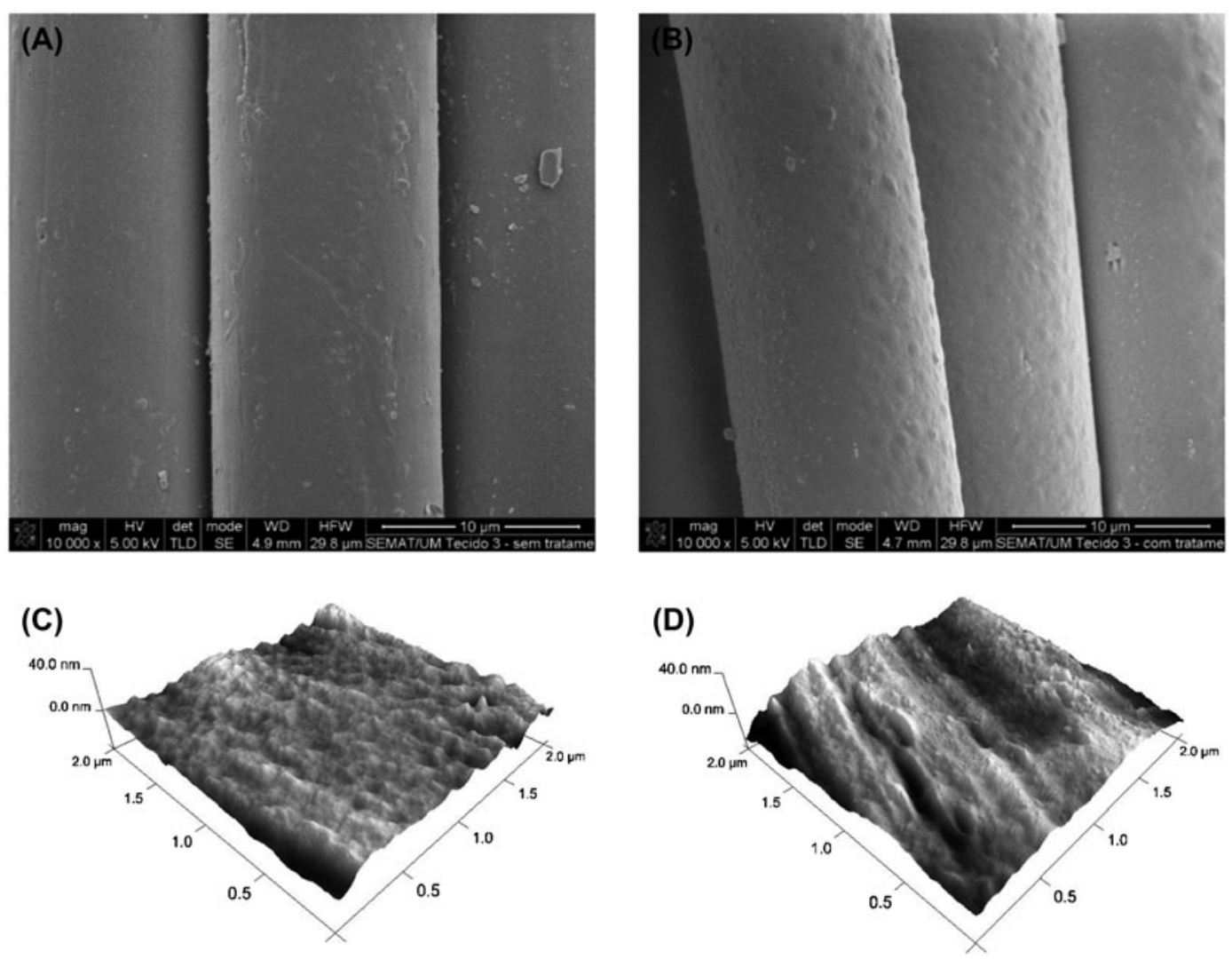

Fig. 3. SEM and AFM images of untreated (A, C) and plasma-treated (B, D) PA66 fibers with a dosage of $2.5 \mathrm{~kW} \mathrm{~min} / \mathrm{m}^{2}$ with magnification of 10,000X.

treatment with non-polymerizing gases that leading in time to significant decreases in wettability and loss of surface oxidation [29], the plasma-treated PA66 does not completely lose its wetting properties and a reasonable value suitable for dyeing at commercial scale is maintained until seven days as previously observed [1]. Dye uptake was monitored measuring both $K / S$ values of the dyed fabrics and dyebath concentrations before and after plasma treatment. As observed in Table 3, the increase in color depth in dyeing of the PA fabric using three different direct dyes simultaneously and two different temperatures shows that dyeing kinetic is greatly influenced by plasma treatment. Dyebath concentration is completely exhausted in the plasma-treated sample; hence this never occurs in the untreated sample. The plasma-treated PA66 dyed at $80^{\circ} \mathrm{C}$ shows higher $K / S$ values than the sample without treatment dyed at $98^{\circ} \mathrm{C}$. These results reveal that plasma treatment can improve PA saturation point.

Table 4 shows the results obtained by washing, light, and rubbing fastness of the PA samples with and without plasma treatment. The results of washing fastness at $40^{\circ} \mathrm{C}$ are very good (values of 4-5) confirming the level of dye diffusion and fixation into the fiber. Values of 4-5 for color staining were also obtained for all the fibers (data not shown) of the multifiber fabric (AC, CO, PA, PES, PAC, and WO). The results of wet and dry rubbing fastness in plasmatreated dyed fabrics are also very good. The value of 5 in the gray scale was obtained for all the samples. The light fastness of PA66 fabrics was evaluated from 2 to $48 \mathrm{~h}$. After short periods of light exposure (2-4 h), dye degradation was dramatically lower in the DBD-treated samples. Also after $24 \mathrm{~h}$ of exposure, DBD-treated samples presented lower dye degradation than control samples. Only after $48 \mathrm{~h}$ of exposure, the color difference between untreated and plasma-treated sample become comparable. The plasma-induced surface modification allows obtaining darker colors, with better fastness properties when compared with the untreated sample.

The results of the effluent recycling show that the dyebath solutions of the three colors are almost 
Table 3

Color strength of untreated (U) and plasma-treated (P) PA66 fabrics dyed at 80 and $98^{\circ} \mathrm{C}$

\begin{tabular}{llllllll}
\hline & \multicolumn{3}{l}{$K / S$ at $80^{\circ} \mathrm{C}$} & & & \multicolumn{2}{l}{$K / S$ at $98^{\circ} \mathrm{C}$} \\
\cline { 2 - 5 } & $\mathrm{U}$ & $\mathrm{P}$ & Ratio $(\mathrm{P} / \mathrm{U})$ & & $\mathrm{U}$ & $\mathrm{P}$ & Ratio $(\mathrm{P} / \mathrm{U})$ \\
\hline Color 1 & 56.25 & 111.08 & 1.97 & 1.91 & 92.26 & 153.61 & 1.66 \\
Color 2 & 50.71 & 97.00 & 2.15 & 81.54 & 134.46 & 1.65 \\
Color 3 & 57.13 & 123.11 & 86.64 & 131.33 & 1.52 \\
\hline
\end{tabular}

Table 4

Fastness properties of untreated (U) and plasma-treated (P) dyed-PA66 fabrics

\begin{tabular}{|c|c|c|c|c|c|c|c|c|c|c|}
\hline & & \multicolumn{2}{|c|}{$\begin{array}{l}\text { Washing fastness (color } \\
\text { change - gray scale) }\end{array}$} & \multirow{2}{*}{ Rubbing fastness (Gray scale) } & \multicolumn{6}{|c|}{ Light fastness $\left(\Delta E^{*}\right)$} \\
\hline & & Dyed at $98^{\circ} \mathrm{C}$ & Dyed at $80^{\circ} \mathrm{C}$ & & $2 \mathrm{~h}$ & $4 \mathrm{~h}$ & $8 \mathrm{~h}$ & $12 \mathrm{~h}$ & $24 \mathrm{~h}$ & $48 \mathrm{~h}$ \\
\hline \multirow[t]{2}{*}{ Color 1} & $\mathrm{U}$ & $3-4$ & 4 & 5 & 3.9 & 4.0 & 5.6 & 6.1 & 8.7 & 9.3 \\
\hline & $\mathrm{P}$ & $4-5$ & 5 & 5 & 1.1 & 2.1 & 3.3 & 4.3 & 6.5 & 8.7 \\
\hline \multirow[t]{2}{*}{ Color 2} & $\mathrm{U}$ & 5 & $4-5$ & 5 & 3.4 & 3.4 & 4.2 & 4.5 & 6.1 & 7.5 \\
\hline & $\mathrm{P}$ & 4 & 4 & 5 & 1.1 & 2.3 & 3.3 & 4.4 & 5.3 & 7.7 \\
\hline \multirow[t]{2}{*}{ Color 3} & $\mathrm{U}$ & $4-5$ & 4 & 5 & 2.0 & 2.8 & 3.6 & 4.3 & 6.0 & 7.6 \\
\hline & $\mathrm{P}$ & 5 & $4-5$ & 5 & 0.9 & 1.5 & 2.7 & 3.2 & 5.4 & 7.9 \\
\hline
\end{tabular}

Table 5

Color strength $(K / S)$, difference of color $\left(\Delta E^{*}\right)$, and washing fastness of PA66 dyed at $98^{\circ} \mathrm{C}$ with the dyeing effluent of the plasma-treated PA66 fabrics

\begin{tabular}{|c|c|c|c|c|c|c|c|c|}
\hline & \multicolumn{2}{|c|}{$\begin{array}{l}\text { 1st Dyeing } \\
(K / S)\end{array}$} & \multicolumn{3}{|c|}{$\begin{array}{l}\text { Recycling dyeing using plasma } \\
\text { effluent }(K / S)\left[\Delta E^{*}\right]\end{array}$} & \multicolumn{3}{|c|}{$\begin{array}{l}\text { Washing fastness } \\
\text { (gray scale - color } \\
\text { change) }\end{array}$} \\
\hline & $\mathrm{U}$ & $\mathrm{P}$ & $1 \mathrm{st}$ & 2 th & 3th & 1st & 2 th & 3th \\
\hline Color 1 & 132.7 & 144.7 & $149.1[0.46]$ & $152.2[0.78]$ & $152.0[1.13]$ & $4-5$ & $4-5$ & $4-5$ \\
\hline Color 2 & 114.8 & 134.6 & 134.1 [0.37] & $132.2[0.53]$ & 133.4 [0.88] & $4-5$ & $4-5$ & 4 \\
\hline Color 3 & 119.9 & 143.0 & $144.5[0.20]$ & $144.0[0.38]$ & 144.1 [0.95] & 5 & $4-5$ & $4-5$ \\
\hline
\end{tabular}

entirely absorbed in the plasma-treated samples, which did not occur in the untreated samples as confirmed by spectrophotometric measures (data not shown). The results obtained were satisfactory, since it was possible to reproduce the standard color during three dyeing cycles using the same effluent with a difference of color $\left(\Delta E^{*}\right)$ within the acceptable range of one unit (Table 5). As might be expected, dyeing in dark color yielded slightly better results than dyeing in bright color. The washing fastness was also evaluated in the samples dyed with the recycled effluent. Values of 4-5 indicate the high fixation and the low concentration of hydrolyzed dyestuff in the dyebath. The complete bath exhaustion was obtained in very short time in all reuse cycles using a plasma-treated fabric that is a very attractive performance regarding industrial application.

\section{Conclusion}

Atmospheric DBD plasma treatment is able to modify PA fabric, chemically and physically, increasing the content of hydrophilic functional groups on the fiber surface in function of the applied dosage. The treated PA66 fabric showed significant improvement in wettability, static contact angle, and wetting time values with an optimal dosage of $2.5 \mathrm{~kW} \mathrm{~min} / \mathrm{m}^{2}$. According to EDS and XPS measurements, plasma reactions are able to change the surface chemistry of the PA66 decreasing the carbon and increasing the oxygen and nitrogen content. Some roughness has been detected in plasma-treated PA66 by SEM and AFM. All these modifications led to a remarkable increase in dyeing rate when compared with untreated samples. All the fastness properties appear to be equivalent or even better with the conventionally dyed 
samples. The obtained complete exhaustion of the dyebath in the plasma-treated PA66 allows the reuse of the same effluent three times for new dyeing processes with excellent level of color uniformity and a difference of color less than 1. Plasma technology can offer a very powerful tool to achieve an environmental friendly process for water saving in textile industry.

\section{Acknowledgment}

Andrea Zille (C2011- UMINHO-2C2T-01) acknowledges funding from Programa Compromisso para a Ciência 2008, Portugal.

\section{References}

[1] F.R. Oliveira, A. Zille, A.P. Souto, Dyeing mechanism and optimization of polyamide 6,6 functionalized with double barrier discharge (DBD) plasma in air, Appl. Surf. Sci. 293 (2014) 177-186.

[2] A. Zille, F.R. Oliveira, A.P. Souto, Plasma treatment in textile industry, Plasma Processes Polym. 12 (2014) 98-131, doi: 10.1002/ppap.201400052.

[3] R. Morent, N. De Geyter, J. Verschuren, K. De Clerck, P. Kiekens, C. Leys, Non-thermal plasma treatment of textiles, Surf. Coat. Technol. 202 (2008) 3427-3449.

[4] C.W. Kan, K. Chan, C.W.M. Yuen, M.H. Miao, Surface properties of low-temperature plasma treated wool fabrics, J. Mater. Process Technol. 83 (1998) 180-184.

[5] F.R. Oliveira, A.P. Souto, N. Carneiro, J.H.O. Nascimento, Surface modification on polyamide 6.6 with double barrier discharge (DBD) plasma to optimise dyeing process by direct dyes, Mater. Sci. Forum 636-637 (2010) 846-852.

[6] L. Schneider, C. Hafner, I.J. Jager, Mutagenicity of textile dye products, J. Appl. Toxicol. 24 (2004) 83-91.

[7] J. Shah, S. Shah, Innovative plasma technology in textile processing: A step towards green environment, Res. J. Eng. Sci. 2 (2013) 34-39.

[8] M.M. El-Zawahry, N.A. Ibrahim, M.A. Eid, The impact of nitrogen plasma treatment upon the physicalchemical and dyeing properties of wool fabric, Polym. Plast. Technol. Eng. 45 (2006) 1123-1132.

[9] J. Yip, K. Chan, K.M. Sin, K.S. Lau, Study of plasmaetched and laser-irradiated polyamide materials, Mater. Res. Innovations 6 (2002) 44-50.

[10] M. Radetic, P. Jovancic, N. Puac, Z.L. Petrovic, Environmental impact of plasma application to textiles, J. Phys. Conf. Ser. 71 (2007) 012017.

[11] A.K. Verma, R.R. Dash, P. Bhunia, A review on chemical coagulation/flocculation technologies for removal of colour from textile wastewaters, J. Environ. Manage. 93 (2012) 154-168.

[12] G. Mezohegyi, F.P. van der Zee, J. Font, A. Fortuny, A. Fabregat, Towards advanced aqueous dye removal processes: A short review on the versatile role of activated carbon, J. Environ. Manage. 102 (2012) 148-164.
[13] R. Dorai, M.J. Kushner, A model for plasma modification of polypropylene using atmospheric pressure discharges, J. Phys. D: Appl. Phys. 36 (2003) 666-685.

[14] F. Huang, Q. Wei, X. Wang, W. Xu, Dynamic contact angles and morphology of PP fibres treated with plasma, Polym. Test. 25 (2006) 22-27.

[15] C. Canal, F. Gaboriau, R. Molina, P. Erra, A. Ricard, Role of the active species of plasmas involved in the modification of textile materials, Plasma Processes Polym. 4 (2007) 445-454.

[16] D. Pappas, A. Bujanda, J.D. Demaree, J.K. Hirvonen, W. Kosik, R. Jensen, S. McKnight, Surface modification of polyamide fibers and films using atmospheric plasmas, Surf. Coat. Technol. 201 (2006) 4384-4388.

[17] U. Stachewicz, A.H. Barber, Enhanced wetting behavior at electrospun polyamide nanofiber surfaces, Langmuir 27 (2011) 3024-3029.

[18] P. Esena, C. Riccardi, S. Zanini, M. Tontini, G. Poletti, F. Orsini, Surface modification of PET film by a DBD device at atmospheric pressure, Surf. Coat. Technol. 200 (2005) 664-667.

[19] C.Q. Wang, X.N. He, Effect of atmospheric pressure dielectric barrier discharge air plasma on electrode surface, Appl. Surf. Sci. 253 (2006) 926-929.

[20] L. Shen, J.J. Dai, Improvement of hydrophobic properties of silk and cotton by hexafluoropropene plasma treatment, Appl. Surf. Sci. 253 (2007) 5051-5055.

[21] Z.S. Cai, Y.P. Qiu, C.Y. Zhang, Y.J. Hwang, M. McCord, Effect of atmospheric plasma treatment on desizing of PVA on cotton, Text. Res. J. 73 (2003) 670-674.

[22] G. Borcia, N. Dumitrascu, G. Popa, Influence of dielectric barrier discharge treatments on the surface properties of polyamide-6 films, J. Optoelectron. Adv. Mater. 7 (2005) 2535-2538.

[23] U. Lommatzsch, D. Pasedag, A. Baalmann, G. Ellinghorst, H.E. Wagner, Atmospheric pressure plasma jet treatment of polyethylene surfaces for adhesion improvement, Plasma Processes Polym. 4 (2007) S1041-S1045.

[24] P.K. Panda, D. Rastogi, M. Jassal, A.K. Agrawal, Effect of atmospheric pressure helium plasma on felting and low temperature dyeing of wool, J. Appl. Polym. Sci. 124 (2012) 4289-4297.

[25] G. Borcia, N. Dumitrascu, G. Popa, Influence of helium-dielectric barrier discharge treatments on the adhesion properties of polyamide-6 surfaces, Surf. Coat. Technol. 197 (2005) 316-321.

[26] N. Dumitrascu, C. Borcia, Adhesion properties of polyamide- 6 fibres treated by dielectric barrier discharge, Surf. Coat. Technol. 201 (2006) 1117-1123.

[27] J. Molina, F.R. Oliveira, A.P. Souto, M.F. Esteves, J. Bonastre, F. Cases, Enhanced adhesion of polypyrrole/PW12O 403- hybrid coatings on polyester fabrics, J. Appl. Polym. Sci. 129 (2013) 422-433.

[28] D. Sun, G.K. Stylios, Investigating the plasma modification of natural fiber fabrics-the effect on fabric surface and mechanical properties, Text. Res. J. 75 (2005) 639-644.

[29] W. Qufu, W. Yingying, Y. Qin, Y. Liangyan, Functionalization of textile materials by plasma enhanced modification, J. Ind. Text. 36 (2007) 301-309. 